\title{
FEDERALISMO, DESENHO CONSTITUCIONAL E INSTITUIÇÕES FEDERATIVAS NO BRASIL PÓS-1988
}

\author{
Celina Souza
}

\section{RESUMO}

O artigo analisa os dispositivos constitucionais relativos ao federalismo ao longo da história constitucional brasileira, buscando conciliar a análise sobre como o federalismo brasileiro funciona na prática e os dispositivos constitucionais que se aplicam a essa instituição. São descritos os diversos desenhos constitucionais da federação brasileira, focalizando principalmente a Constituição Federal de 1988 e suas emendas. $O$ artigo argumenta que os principais constrangimentos enfrentados hoje pelo federalismo brasileiro decorrem mais da dificuldade dos governos de redirecionar o rumo de certas políticas públicas e de lidar com questões macro-econômicas não-antecipadas pelos constituintes de 1988 do que de problemas decorrentes do desenho constitucional.

PALAVRAS-CHAVE: federalismo; constitucionalismo; Brasil.

\section{INTRODUÇÃO}

Há mais de um século, o Brasil adotou a forma federativa de divisão territorial de governo. Ao longo desse tempo, o país conviveu com grande variedade de arranjos federativos e experimentou períodos de autoritarismo e de regime democrático. Durante a vigência das sete constituições que regeram as instituições brasileiras após a República, as regras relativas ao federalismo fizeram parte integrante do corpo constitucional - daí a importância de estudar-se o federalismo brasileiro associando-o ao tema do constitucionalismo. Pela interseção entre as regras que regem o federalismo e sua constitucionalização, torna-se importante atender à convocação de Dearlove (apud EVANS, 2001) de "trazer a constituição de volta" como foco dos trabalhos sobre federalismo no âmbito da Ciência Política. Isso porque a teoria constitucional busca respostas para questões políticas fundamentais que afetam os entes constitutivos da federação, tais como "quem governa, como se governa e quem deveria governar” (EVANS, 2001).

Apesar das controvérsias sobre as principais características dos sistemas federativos, existe um consenso de que essa instituição tem duas dimensões principais: desenho constitucional e divisão territorial de poder governamental. Embora outros fatores e instituições também sejam objeto de análise sob a ótica do federalismo, tais como as dinâmicas da economia política, da competição partidária e da chamada cultura política, as manifestações territoriais do federalismo requerem uma análise não apenas de sua aplicação prática, mas também do ponto de vista das constituições. Essas manifestações territoriais dizem respeito à divisão de competências entre os entes constitutivos e no poder Legislativo, ao papel do poder Judiciário, à alocação de recursos fiscais e de responsabilidades entre os entes constitutivos da federação e suas garantias constitucionais.

A análise do federalismo brasileiro ainda estabelece escassas ligações com a teoria constitucional propriamente dita e também raramente focaliza as instituições políticas estabelecidas constitucionalmente que regem o federalismo. Embora aspectos importantes do sistema político brasileiro que influenciam a divisão territorial de poder e de governo sejam objeto de vários análises por cientistas políticos, inclusive norte-americanos, tais como as realizadas sobre o sistema presidencial e o sistema eleitoral, outras questões que influenciam o federalismo e que foram constitucionalizadas, tais como o sistema fiscal, permanecem pouco analisadas pela Ciência Política ${ }^{1}$. Devido à importância que a descentralização assumiu no

\footnotetext{
${ }^{1}$ Para uma excelente análise sobre a contribuição da Ciência Política para o entendimento do federalismo brasileiro, ver Almeida (2001)
} 
Brasil posterior a 1988, a maioria dos trabalhos focaliza o federalismo mais como sinônimo de descentralização, aliando-se ao que Gibson (2004) classificou como a escola do federalismo como descentralização, do que associando o federalismo a uma ordem política e constitucional com especificidades próprias. Muitos trabalhos também analisam as relações que se estabelecem entre esferas de governos, focalizando as chamadas relações intergovernamentais, também como resultado da emergência de políticas descentralizadas, mas sobretudo pelo considerável aumento de programas “intergovernamentalizados”, tendência observada na maioria dos países federais e unitários.

O sistema federal foi introduzido em 1889 e detalhado na Constituição de 1891. Como sabemos, e diferentemente de muitas federações, a brasileira nunca foi uma resposta às clivagens sociais decorrentes de conflitos étnicos, lingüísticos ou religiosos. Movimentos separatistas ocorreram apenas durante o período colonial e no início do século XIX a unidade do país não era questionada. Por isso, as constituições brasileiras não prevêem regras para a secessão e a de 1988 ainda estabelece que nenhuma emenda constitucional pode abolir a "forma federativa de Estado”. Dado que a unidade do país não se constitui em ameaça, as constituições sempre declararam que "todo o poder emana do povo" e não da nação, do Estado ou das unidades constitutivas da federação, como ocorre em muitos países federais, sinalizando que o sistema federativo brasileiro está assentado no princípio do individualismo e não no das instituições coletivas. Nesse sentido, o constitucionalismo brasileiro aproxima-se da tradição norte-americana, em que, baseada na concepção lockeana, os direitos fundamentais têm sua origem nos indivíduos, distanciando-se da tradição da Europa continental, onde o Estado é a fonte dos direitos fundamentais ${ }^{2}$.

A federação foi criada a partir das 20 províncias herdadas do sistema unitário, contando hoje com 26 estados, o Distrito Federal e 5561 municípios, distribuídos em cinco regiões. Existe um consenso de que as heterogeneidades econômicas entre as regiões constituem-se no principal

\footnotetext{
2 Sobre as diferenças entre o constitucionalismo da Europa continental e dos Estados Unidos, ver Rosenfeld (2000).
}

problema do federalismo brasileiro e os dados mostram que a concentração econômica regional aumentou nos anos 1990, após leve declínio registrado durante o regime militar. Tal declínio não deve ser creditado, todavia, à centralização fiscal daquele regime nem à sua característica autoritária, mas sim às altas taxas de crescimento econômico registradas por quase uma década, de cerca de $10 \%$ a. a., que permitiram aos formuladores de políticas públicas a adoção de políticas voltadas para amenizar o desequilíbrio econômico entre as regiões.

Este artigo busca suprir a lacuna da ainda escassa atenção ao desenho constitucional do federalismo no Brasil nos trabalhos da Ciência Política. Nesse sentido, o artigo busca conciliar a análise sobre como o federalismo brasileiro funciona na prática com os dispositivos constitucionais que a ele aplicam-se, apesar do alerta de Riker (1975), de que, para entendermos o funcionamento dos sistemas federais, não é necessário compreender a estrutura constitucional, mas sim as forças reais do sistema político, os sistemas de partidos nacionais, as práticas políticas e as estruturas do poder econômico. No entanto, dada a carência de trabalhos na Ciência Política voltados para "trazer a constituição de volta”, e embora concordando com Riker - que a estrutura constitucional não prediz, por si só, o impacto causal das instituições federais ou a dinâmica política interna das federações -, a descrição e a análise da estrutura constitucional pode ajudar-nos a compreender melhor como o federalismo opera, principalmente em um país como o Brasil, que possui uma história constitucional complexa e onde o federalismo sempre assumiu realce nos dispositivos constitucionais.

O artigo descreve os diversos desenhos constitucionais da federação brasileira, focalizando principalmente a Constituição Federal de 1988 e suas emendas. Argumento, em consonância com Riker, que os principais constrangimentos enfrentados hoje pelo federalismo brasileiro decorrem, em parte, mais da dificuldade dos governos de redirecionar o rumo de certas políticas públicas e de lidar com questões macro-econômicas nãoantecipadas pelos constituintes de 1988 do que de problemas decorrentes do desenho constitucional. Isso mostra que existe uma distância entre os dispositivos constitucionais e as circunstâncias políticas e econômicas, com as últimas prevale- 
cendo sobre os mandamentos constitucionais. Argumento, ainda, que esse desenho acomoda as clivagens regionais existentes no território, que geram, também, formas assimétricas de distribuição de poder territorial ${ }^{3}$.

O artigo está dividido em seis seções. A próxima descreve os dispositivos constitucionais sobre a federação inscritos nas constituições anteriores à de 1988, enquanto a seção seguinte focaliza a Constituição em vigor. A seção IV analisa os princípios constitucionais da federação; a V trata da estrutura e do funcionamento do sistema federativo, detalhando suas principais instituições do ponto de vista constitucional; a VI é dedicada ao financiamento das instâncias federativas; a seção VII discute brevemente as principais mudanças constitucionais que afetam as esferas de governo e a última seção apresenta algumas conclusões.

\section{FEDERALISMO NAS CONSTITUIÇÕES ANTERIORES A $1988^{4}$}

O desenho do federalismo brasileiro pode ser mais bem compreendido por meio de uma breve descrição das constituições anteriores a 1988. Isso porque as constituições refletiram as barganhas políticas e territoriais que ocorreram ao longo da nossa história. Além disso, essas constituições, enquanto refletiam as mudanças nos regimes políticos, também mantiveram ou fortaleceram muitos dispositivos constitucionais das constituições anteriores, com poucas exceções.

Debates sobre a divisão territorial de poder tiveram início muito antes do fim da era colonial e o principal objetivo do movimento republicano era o federalismo e não a liberdade, como nos mostram os historiadores (CARVALHO, 1993). No entanto, federalismo (associado à descentralização) e liberdade eram tratados como sinônimos. A op-

3 Esse argumento está mais elaborado em Souza (1997; 2002; 2003). Gibson e Falleti (2004) desenvolvem o mesmo argumento para a constituição e para os futuros desdobramentos da Argentina como federação. Gibson (2004, p. 14) argumenta, ainda, que a assimetria de poder entre os entes constitutivos da federação, ou seja, os estados, tem sido largamente ignorada nas análises teóricas dos sistemas federais, mais influenciadas pelos conflitos intergovernamentais, ou seja, entre o governo federal e as esferas subnacionais.

4 Esta seção é uma versão resumida de artigo publicado anteriormente; ver Souza (2001a). ção pelo federalismo, apesar de ser inspirada na experiência dos EUA, não foi uma simples cópia daquele sistema porque sua adoção foi precedida de debates e porque as elites regionais eram favoráveis à descentralização, vista como sendo alcançável por um sistema federal e não por um sistema unitário. Apesar de algumas instituições norte-americanas como o sistema presidencialista, o federalismo e o controle de constitucionalidade terem sido adotadas como uma das bases das instituições políticas brasileiras e, apesar da influência, mais tarde, das constituições de Weimar e do México na constitucionalização dos direitos sociais, o Brasil construiu sua própria história constitucional ao longo da elaboração de suas sete constituições.

A primeira Constituição escrita do Brasil foi promulgada em 1824, após a independência de Portugal. Essa Constituição delegou poderes administrativos às então 16 províncias. Embora as províncias não contassem com autonomia política formal ou informal, essa delegação foi interpretada como abrindo o caminho para uma futura federação.

A Constituição de 1891, promulgada após a República, seguiu a promessa descentralizadora do mote republicano: centralização, secessão; descentralização, unidade. Por essa Constituição, recursos públicos foram canalizados para alguns poucos estados, mostrando que a federação brasileira nasceu sob a égide da concentração de recursos em poucos estados e escassas relações existiam entre os entes constitutivos da federação, caracterizando esse período como o de uma federação isolada.

Esse isolamento foi interrompido em 1930, com o golpe de Vargas. Um das primeiras medidas após o golpe foi perdoar as dívidas dos estados com a União, inclusive a maior de todas, a de São Paulo, contraída por força dos subsídios ao café, pacificando, assim, os possíveis descontentamentos das elites regionais (LOVE, 1993). Em 1932, Vargas aprovou uma reforma eleitoral, que, entre outras medidas, aumentou a representação política dos estados menos populosos na Câmara dos Deputados. Concebida como forma de contrabalançar o poder de alguns poucos estados, no que ficou conhecida como a política dos governadores, a sobre-representação dos estados menos populosos permanece como um dos mecanismos voltados para o amortecimento das 
heterogeneidades regionais e como forma de acomodar as assimetrias de poder entre unidades territoriais que registram grandes diferenças econômicas.

A Constituição de 1934, escrita como resultado do golpe de 1930, introduziu a tendência à constitucionalização de questões sócio-econômicas e expandiu as relações intergovernamentais pela autorização para que o governo federal concedesse às instâncias subnacionais recursos e assistência técnica. Aos municípios foram assegurados recursos próprios, que seriam por eles coletados, passando também a receber parcela de um imposto estadual. A peculiaridade dessa Constituição frente às demais é que o Senado Federal foi reduzido a órgão colaborador da Câmara dos Deputados.

A constituição seguinte foi promulgada por Vargas, em 1937, após o golpe militar por ele liderado. Vargas fechou o Congresso Nacional e as assembléias estaduais e substituiu os governadores eleitos por interventores. Existe um consenso de que uma das principais razões do golpe seria neutralizar a importância dos interesses regionais a fim de construir a unidade política e administrativa necessária para promover a chamada modernização social e econômica do país. Um dos atos mais simbólicos de Vargas contra os interesses regionais foi queimar todas as bandeiras estaduais em praça pública. Os governos subnacionais perderam receitas para a esfera federal mas a mais importante medida foi delegar ao governo federal a competência para legislar sobre as relações fiscais externas e entre os estados. Ao negar aos governos estaduais o direito de decidir sobre um dos mais importantes aspectos de sua vida econômica, ou seja, a definição das regras de trocas de mercadorias, Vargas pavimentou o caminho para a industrialização. Os desequilíbrios financeiros entre os estados não só persistiram mas aumentaram: em 1945, três estados concentravam mais de $70 \%$ das receitas estaduais (MAHAR, 1976, p. 415).

Com o retorno do regime democrático, nova Constituição foi escrita, a de 1946. Inicialmente influenciada por ideais liberais, eles não prevaleceram devido ao reconhecimento de que era preciso perseguir rápido crescimento econômico sob a égide do governo federal. No entanto, como democracia e descentralização foram transformando-se, ao longo da história, em “afinidades eletivas”, os recursos para os governos locais foram privilegiados vis-à-vis os dos estados ${ }^{5}$. A Constituição de 1946 introduziu o primeiro mecanismo de transferências intergovernamentais da esfera federal para as municipais, excluídos os estados, na tentativa de diminuir os desequilíbrios verticais de receita, mas o critério de transferência não continha nenhum mecanismo de equalização fiscal, dado que consistia em dividir o montante a ser transferido pelo número de municípios existentes (REZENDE, 1976, p. 238). A questão dos desequilíbrios horizontais também foi parcialmente introduzida pela destinação de recursos federais para as regiões economicamente mais pobres. Essas medidas, no entanto, tiveram efeito reduzido devido ao crescimento das atividades federais, ao aumento do número de novos municípios, à inflação e ao não-pagamento das quotas federais aos municípios (MAHAR, 1976, p. 241).

A Constituição de 1946 ainda manteve a marca de ter sido a de vida mais longa da história constitucional brasileira. Seus dispositivos e o regime democrático por ela regulado sobreviveram a várias crises políticas: suicídio de Vargas, renúncia de Jânio Quadros e posse de João Goulart. No entanto, não foi capaz de sobreviver à crise econômica e política iniciada em meados dos anos 1960.

O golpe de 1964 colocou o Brasil na rota dos regimes autoritários que passaram a governar a América Latina nos anos 1960. Paradoxalmente, os militares não promulgaram imediatamente uma nova Constituição, embora tenham feito várias emendas à Constituição de 1946. A nova Constituição do regime só foi promulgada em 1967 e em 1969 uma longa emenda constitucional foi editada. Como se sabe, a Constituição de 1967-1969 e a reforma tributária de 1966 centralizaram na esfera federal poder político e tributário, afetando o federalismo e suas instituições. Isso não significou, todavia, a eliminação do poder dos governadores nem dos prefeitos das principais capitais. Como demonstraram Medeiros (1986) e Ames (1987), os governantes subnacionais foram grandes legitimadores do regime militar e contribuíram para formar as coalizões necessárias à sua longa sobrevivência.

\footnotetext{
5 Sobre a influência das demandas municipais na constituinte de 1946, ver Melo (1993).
} 
No entanto, apesar da centralização dos recursos financeiros, foi a reforma tributária dos militares que promoveu o primeiro sistema de transferência intergovernamental de recursos da esfera federal para as subnacionais, por meio dos fundos de participação (Fundo de Participação dos Estados (FPE) e Fundo de Participação dos Municípios (FPM)). O critério de distribuição abandonou a repartição uniforme entre os entes constitutivos, passando a incorporar o objetivo de maior equalização fiscal pela adoção do critério de população e inverso da renda per capita. No regime militar, as esferas subnacionais também recebiam as chamadas transferências negociadas, que cresceram significativamente no período.

Muitos trabalhos foram produzidos sobre os efeitos da centralização fiscal sobre o federalismo. Esses trabalhos podem ser divididos em dois grupos. Um primeiro grupo, que se concentrou nas contas públicas, mostrou que a posição financeira dos municípios havia melhorado no período, ao contrário do que aconteceu com os estados (GRAHAM, 1987; SERRA \& AFONSO, 1991). Outro grupo interpretou a dependência política e financeira e de políticas públicas dos entes subnacionais como um rompimento do regime federativo e da federação (MELLO, 1976) ou como o exemplo de uma federação mais formal, que mascarava a existência de um Estado unitário (SELCHER, 1989).

\section{A CONSTITUIÇÃO DE 1988}

A redemocratização trouxe como uma de suas principais bandeiras a "restauração" do federalismo e a descentralização por meio da elaboração de uma nova constituição. Esse compromisso fazia parte do Manifesto à Nação divulgado pelos partidos que compunham a chamada Aliança Democrática, constituída em torno da candidatura presidencial de Tancredo Neves. O compromisso de elaborar uma nova carta constitucional gerou entusiasmo e otimismo sobre o futuro do país e durante 20 meses o Congresso Nacional e Brasília foram o centro da vida política brasileira, promovendo um visível exercício de participação política. As regras de funcionamento da Assembléia Nacional Constituinte já sinalizavam que a elaboração da Constituição seria um processo bottomup, dado que não haveria apenas uma comissão para propor uma primeira versão da Constituição, mas sim 24 subcomissões, que mais tarde constituiriam oito comissões, seguida de uma comissão de sistematização, que contava com 97 parlamentares, e sessões plenárias com duas rodadas de votações nominais. Outras inovações foram a permissão para o recebimento de propostas de fora do Congresso, caso contassem com a assinatura de 30 mil eleitores, e o envio de sugestões pelo correio ${ }^{6}$.

A Constituição de 1988 foi a mais detalhada de todas as constituições brasileiras. Quando aprovada, continha 245 artigos e mais 70 no capítulo sobre as Disposições Constitucionais Transitórias. Com as emendas constitucionais posteriores, o texto constitucional foi expandido para 250 artigos no corpo constitucional e para 94 nas Disposições Constitucionais Transitórias, número semelhante aos das constituições da Índia e da África do Sul. A tendência à constitucionalização de questões consideradas importantes pode ser, portanto, parcialmente creditada às incertezas decorrentes das mudanças de regime político ocorridas nesses três países. No caso do Brasil, também parece refletir uma reação ao descaso do regime anterior em relação aos dispositivos e constrangimentos constitucionais 7 . Dessa tendência à constitucionalização resultou uma Constituição que regula não apenas princípios, regras e direitos individuais, coletivos e sociais -, mas também um amplo leque de políticas públicas.

A questão sobre a divisão “ótima” entre o que deve ou não ser constitucionalizado é matéria de amplo debate, principalmente entre juristas e economistas da área fiscal ${ }^{8}$. O debate é importante porque envolve a decisão sobre que matérias devem ser objeto de quorum qualificado ou de supermaiorias, que matérias ficam excluídas do processo político (as cláusulas pétreas das constituições) e quais as que ficam submetidas às decisões majoritárias, ou seja, aquelas que devem ser objeto de leis ordinárias. Além do mais, o tema da constitucionalização remete também à capacidade do governo de implementar os dispositivos constitucionais e como proceder quando as circunstâncias mudam.

\footnotetext{
6 Para mais detalhes sobre esse processo, ver Souza (2001b).

7 Esse argumento é do ex-Senador Waldek Ornelas, desenvolvido no seminário sobre federalismo realizado na Universidade de São Paulo em novembro de 2002.

8 Sobre esse debate entre juristas norte-americanos, ver Valente (2001).
} 
A Constituição de 1988 apresenta algumas peculiaridades em relação às constituições anteriores. A primeira é que não foi produto de um texto desenhado por especialistas, especialmente juristas, como aconteceu em 1891 e em 1934, nem se espelhou em constituições anteriores, como em 1946. A segunda é que as constituições anteriores foram o resultado de um processo de ruptura política que já ocorrera, ao passo que em 1988 sua elaboração ocorreu ainda como parte do processo de transição democrática (WERNECK VIANNA, 1999). A terceira inovação, e mais diretamente relacionada com o federalismo, é que aos constituintes foi permitido decidir sobre a manutenção ou não do sistema federativo, proibido na convocação das constituintes anteriores.

Embora a Constituição de 1988 não tenha sido precedida de debates sistemáticos como nos EUA, reunidos em ensaios que ficaram conhecidos como O federalista ${ }^{9}$, houve ampla divulgação de sua pauta e do trabalho da Comissão Afonso Arinos, que a precedeu. Ademais, suas regras foram capazes de conciliar os interesses de novos e velhos atores políticos e grupos de interesse. Essa opção pela conciliação pode ser também um dos fatores explicativos de por que a Constituição tornou-se tão detalhada e por que contém muitos dispositivos que requerem regulamentação posterior, apesar de seu alto nível de detalhe, alguns exigindo leis complementares e outros leis ordinárias ${ }^{10}$. O consenso foi o caminho possível pela ausência de uma clara maioria partidária ou ideológica.

Devido às razões acima expostas, os constituintes tiveram vários incentivos para desenhar uma federação em que o poder governamental foi descentralizado e em que vários centros de poder, embora assimétricos, tornaram-se legitimados para tomar parte do processo decisório.

Em algumas questões, a Constituição de 1988 contrastou com as anteriores, principalmente nos seguintes aspectos: (a) na provisão de mais recursos para as esferas subnacionais; (b) na expansão dos controles institucionais e societais sobre os três níveis de governo, pelo aumento das

\footnotetext{
9 Sobre esse ponto, ver Limongi (1989).

10 Segundo levantamento de Rosenn (1990, p. 778), a Constituição requeria a elaboração de 285 leis ordinárias e 41 complementares.
}

competências dos poderes Legislativo e Judiciário e pelo reconhecimento dos movimentos sociais e de organismos não-governamentais como atores legítimos de controle dos governos e (c) pela universalização de alguns serviços sociais, em particular a saúde pública, antes restrita aos trabalhadores do mercado formal, tendo como princípio diretivo a descentralização e a participação dos usuários.

No entanto, a Constituição de 1988 conservou certas características das constituições anteriores, tais como (a) a tendência à constitucionalização de muitas questões, mantida nas emendas constitucionais aprovadas posteriormente; (b) o fortalecimento dos governos locais vis-à-vis os estados; (c) a tendência à adoção de regras uniformes para as esferas subnacionais, em especial as instâncias estaduais, dificultando a adoção de políticas próximas de suas prioridades, e (d) a impossibilidade de avançar em políticas voltadas para a diminuição dos desequilíbrios regionais, apesar da existência de mecanismos constitucionais que ou não foram operacionalizados ou são insuficientes para uma efetiva política de equalização fiscal.

\section{PRINCÍPIOS CONSTITUCIONAIS DA FE- DERAÇÃO}

\section{IV.1. Federalismo ${ }^{11}$}

Diferentemente de muitas federações, a brasileira, assim como a belga, é um sistema de três níveis (triplo federalismo) porque incorporou os municípios, juntamente com os estados, como partes integrantes da federação, refletindo uma longa tradição de autonomia municipal e de escasso controle dos estados sobre as questões locais.

Como se sabe, os três níveis de governo têm seus próprios poderes legislativos e os níveis federal e estaduais têm seus próprios poderes judiciários. Os estados são representados no Senado Federal mas não no Executivo, embora informalmente se mantenha a tradição de assegurar a representação dos interesses de vários estados no poder Executivo federal por meio da indicação para cargos, os quais combinam, em geral, filiação

11 Para uma visão das principais características institucionais dos países federais, ver Griffiths (2002). 
partidária com os interesses das lideranças estaduais que integram a coalizão de apoio ao poder Executivo federal.

Apesar de a Constituição de 1988 ter reduzido o número de casos em que o governo federal pode intervir nos estados e os estados nos municípios, o instituto da intervenção ainda vigora, embora sujeito à aprovação legislativa. Pedidos para a presença do Exército nas grandes cidades por força de questões como o aumento da violência e greves das polícias militares estaduais têm reacendido o debate sobre a intervenção, que, no caso brasileiro, inclui um dispositivo que desestimula seu uso, dado que emendas constitucionais são proibidas na vigência da intervenção.

Desde a promulgação da Constituição de 1988, outorgar o rótulo de centralizado ou descentralizado ao federalismo brasileiro parece não dar conta da sua atual complexidade. A federação tem sido marcada por políticas públicas federais que se impõem às instâncias subnacionais, mas que são aprovadas pelo Congresso Nacional e por limitações na capacidade de legislar sobre políticas próprias - esta última também constrangida por decisões do poder Judiciário. Além do mais, poucas competências constitucionais exclusivas são alocadas aos estados e municípios, como também ocorre em outros países em desenvolvimento, tais como o México e a África do Sul. Por outro lado, estados e municípios possuem autonomia administrativa considerável, responsabilidades pela implementação de políticas aprovadas na esfera federal, inclusive muitas por emendas constitucionais, e uma parcela dos recursos públicos poucas vezes concedida pelas constituições anteriores, em particular para os municípios, superior a outros países em desenvolvimento.

\section{IV.2. Estatuto dos entes constitutivos}

Do ponto de vista constitucional, todas as unidades constitutivas possuem poderes e competências iguais, como ocorre nos EUA e no México. Nesse sentido, o Brasil adotou um modelo de federalismo simétrico em uma federação assimétrica. Dois fatores fortalecem ainda mais esse modelo simétrico. O primeiro é que as regras sobre as competências, recursos e políticas públicas das entidades subnacionais são capítulos detalhados da Constituição, deixando pouca margem de manobra para iniciativas específicas. O segundo é que o Supremo Tribunal Federal (STF) vem decidindo sistematicamente que as constituições e as leis estaduais reflitam os dispositivos federais ou são monopólios federais, o que impõe uma hierarquia das normas constitucionais e legais, apesar da Constituição não explicitar tal princípio. Como argumentam Oscar Vilhena e Werneck Vianna (1999), todo Direito relevante é um Direito federal ${ }^{12}$. Os estados acabam sendo quase apenas entes gestores do Direito federal.

Diferentemente de federações como a Austrália, Índia, México, Suíça e EUA, onde emendas à Constituição federal devem ser ratificadas pelas assembléias estaduais ou via referendo, essa exigência não existe no Brasil, onde se assume que os representantes dos estados no Senado Federal são os guardiões dos interesses estaduais.

Apesar de os estados terem constituições próprias, todas aprovadas em 1989, e apesar de as regras constitucionais federais estabelecerem que essas constituições deveriam "obedecer aos princípios” da Constituição federal, a maioria das constituições estaduais é uma mera repetição dos mandamentos federais. As poucas tentativas de criar regras não explicitamente especificadas pela Constituição federal, mas não proibidas, foram declaradas inconstitucionais pelo STF. Isso se deve menos ao fato de que a Constituição de 1988 ser extremamente detalhada e mais à interpretação do STF, referida acima, de que as constituições e as leis estaduais devem ser subsumidas pelo que dispõe a legislação federal.

\section{IV.3. Distribuição de competências entre os entes} constitutivos

As constituições brasileiras sempre detalharam as competências dos três níveis de governo, embora a de 1988 seja a mais detalhada. A União detém o maior e o mais importante leque de competências exclusivas. Apesar da competência residual ser dos estados, tal como nos EUA, Austrália e México, o alto nível de detalhe da Constituição de 1988 deixa pouco espaço para o exercício da competência residual.

No que se refere às competências concorrentes, os constituintes de 1988 fizeram uma clara

\footnotetext{
$12 \mathrm{O}$ argumento de Oscar Vilhena foi desenvolvido em um seminário sobre federalismo ocorrido na Universidade de São Paulo em novembro de 2002.
} 
opção pelo princípio de que a responsabilidade pela provisão da maioria dos serviços públicos, em especial os sociais, é comum aos três níveis, como mostra a Tabela $1^{13}$. Isso gera debates acalorados sobre qual nível é responsável por qual política ou serviço público. Tal debate, que resulta, muitas vezes, em trocas de acusações entre governantes, desconsidera que os constituintes optaram por uma divisão institucional de trabalho entre os entes federativos claramente compartilhada, sinalizando que o federalismo brasileiro teria um caráter mais cooperativo do que dual ou competitivo. No entanto, e apesar do grande nú- mero de competências concorrentes, na prática existem grandes distâncias entre o que prevê a Constituição e sua aplicação. O objetivo do federalismo cooperativo está longe de ser alcançado por duas razões principais. A primeira está nas diferentes capacidades dos governos subnacionais de implementarem políticas públicas, dadas as enormes desigualdades financeiras, técnicas e de gestão existentes. A segunda está na ausência de mecanismos constitucionais ou institucionais que estimulem a cooperação, tornando o sistema altamente competitivo.

TABELA 1 - COMPETÊNCIAS CONCORRENTES

\begin{tabular}{|l|l|}
\hline \multicolumn{1}{|c|}{ ESFERA DE GOVERNO } & \multicolumn{1}{|c|}{ SERVIÇO/ATIVIDADE } \\
\hline Federal-estadual-Iocal \\
(competências partilhadas) & Saúde e assistência pública \\
& Assistência aos portadores de deficiência \\
& Preservação do patrimônio histórico, artístico, cultural, paisagens \\
& naturais notáveis e sítios arqueológicos \\
& Proteção do meio ambiente e dos recursos naturais \\
& Cultura, educação e ciência \\
& Preservação das florestas, da fauna e da flora \\
& Agropecuária e abastecimento alimentar \\
& Habitação e saneamento \\
& Combate à pobreza e aos fatores de marginalização social \\
& Exploração das atividades hídricas e minerais \\
& Segurança do trânsito \\
& Políticas para pequenas empresas \\
& Turismo e lazer \\
\hline
\end{tabular}

FONTE: Brasil (1988).

Diante do exposto, pode-se afirmar que a lógica que rege a distribuição de competências entre os entes constitutivos da federação é paradoxal. Por um lado, os constituintes decidiram reduzir os recursos financeiros federais vis-à-vis os outros dois níveis de governo, situação que foi parcialmente revertida ao longo dos últimos anos. Por outro lado, os constituintes aumentaram as com-

13 A existência de grande número de competências partilhadas entre diferentes níveis de governo não é uma peculiaridade brasileira. Pesquisa realizada pela Universidade Pompeu Fabru, de Barcelona, identificou que a jurisdição sobre programas sociais é altamente compartilhada entre a esfera federal, os estados e os municípios, principalmente na Alemanha, no Canadá, na Austrália, na Suíça e nos EUA (AGRANOFF, 2003). petências legislativas e de jurisdição do governo federal, ao mesmo tempo em que aumentaram o leque das competências concorrentes.

A questão das competências remete à pergunta de como o poder dos chefes dos poderes executivos federal e estaduais está formal e informalmente distribuído na federação brasileira após a redemocratização. A literatura é controversa sobre esse ponto. Uma corrente, representada pelos trabalhos de Abrúcio (1998), Mainwaring (1999), Ames (2000) e Stepan (2000), argumenta que a federação é dominada pelos interesses estaduais. Várias são os argumentos apresentados, mas a maioria das razões explicativas recai sobre o desenho das instituições políticas brasileiras, que eleva o poder informal que os governadores exercem sobre os parlamentares de seus estados no Congresso Nacional. Essa corrente associa essa 
divisão informal e formal de poder a problemas de governabilidade e à paralisia decisória ${ }^{14}$.

Outra corrente analisa a divisão de poder dentro da federação como fragmentada entre vários centros de poder, embora com capacidades desiguais, mas que competem entre si. A partir dessa perspectiva, os governos federal e estaduais partilham o poder de deliberar sobre questões que afetam seus interesses ${ }^{15}$. Essa visão argumenta que após a redemocratização a divisão formal e informal de poder entre os poderes executivos federal e estaduais passou por três fases. A primeira foi fortemente marcada pelo papel crucial que os governadores eleitos em 1982 exerceram na campanha das Diretas Já, tornando-os uns dos principais fiadores da redemocratização (SALLUM JÚNIOR, 1996), daí resultando a grande influência dos interesses subnacionais na constituinte de 1987-1988. A segunda fase foi marcada pelas dificuldades iniciais de adaptação dos representantes dos entes federativos às novas regras constitucionais. Nessa fase, a disputa entre os interesses dos governadores legitimados pelas eleições de 1986 e de um Presidente que carecia de legitimidade e que se colocara, sistematicamente, contra as decisões tomadas pelos constituintes, foi por mim classificada como a de uma "arena competitiva paralisada” (SOUZA, 1997), porque os escassos canais de negociação intergovernamental encontravam-se bloqueados. Nessa fase, o Congresso Nacional exerceu o papel de mediador desses conflitos. Um exemplo claro, relatado por Kugelmas, Sallum Júnior e Graeff (1989), ocorreu nas negociações do primeiro orçamento federal aprovado após as mudanças promovidas pela Constituição, quando o poder Executivo federal incluiu entre suas receitas parcela advinda da cobrança das dívidas estaduais, medida contestada pelos governadores. O impasse foi intermediado pela Comissão de Orçamento do Congresso pela falta de entendimento entre os

\footnotetext{
14 Sobre o debate da relação entre as instituições políticas brasileiras e a governabilidade, ver Palermo (2000).

15 Ver, entre outros, Souza (1997; 2001b; 2002). Embora não tratando diretamente da divisão de poder entre os entes constitutivos da federação, os trabalhos de Argelina Figueiredo e de Fernando Limongi demonstram o sucesso do Executivo federal em fazer aprovar no Congresso Nacional questões do seu interesse. Ver, principalmente Figueiredo e Limongi (1999).
}

poderes executivos federal e estaduais. A terceira fase iniciou-se com o sucesso do Plano Real no controle da inflação, quando o governo federal começou a recuperar suas perdas de receitas. Essas três fases mostram que os poderes executivos das duas esferas governamentais não eram nem são atores passivos e que a divisão de poder dentro da federação brasileira sinaliza a existência de conflitos e negociações em torno dos interesses dos entes federados.

Na visão de muitos juristas, a divisão de poder favorece a União devido ao seu papel central na definição de políticas, à carência de recursos financeiros de muitos estados e ao excessivo poder de legislar, que promove uniformidade nos governos e nas políticas estaduais ${ }^{16}$.

Outros analistas argumentam que a divisão de poder favorece ao governo local, que vem expandindo sua autonomia ao longo da história. Essa interpretação, todavia, não encontra fundamentação na teoria do federalismo, que considera apenas as esferas federal e estadual de governo. Assim, a relativa importância financeira do município brasileiro e seu papel de principal provedor de importantes políticas sociais não é matéria propriamente concernente à teoria do federalismo e sim dos conceitos de descentralização e de relações intergovernamentais. Dado que a teoria do federalismo não incorpora a situação de espaços territoriais que possuem garantias constitucionais próprias, inclusive tributárias, como é o caso dos municípios brasileiros, os conceitos de relações intergovernamentais e descentralização-centralização seriam os mais apropriados para analisar situações como a brasileira, tornando-se de crucial importância para o melhor entendimento de como o federalismo atua na prática. O uso desses dois conceitos pode iluminar a análise sobre a distribuição de poder territorial em países como o Brasil, onde os municípios assumem papel de destaque, não apenas pela existência de políticas descentralizas, mas pelo seu relativo descolamento da jurisdição dos estados.

Nenhum mecanismo ou instituição regulando as relações intergovernamentais está previsto na Constituição de 1988. O parágrafo único do artigo 23 estabelece que "lei complementar fixará normas para a cooperação entre a União e os Es-

16 Ver, entre outros, Bercovici (2003). 
tados, Distrito Federal e os Municípios, tendo em vista o equilíbrio do desenvolvimento e do bemestar em âmbito nacional” (BRASIL, 1988). No entanto, tal lei nunca foi proposta pelo poder Executivo ao Congresso Nacional e não existem sinais de que esteja na agenda dos entes governamentais. Isso não significa, todavia, que as relações intergovernamentais são inexistentes. Os governos subnacionais partilham recursos federais, os municípios partilham parcelas de impostos estaduais e existem várias políticas sociais, particularmente saúde e educação fundamental, que contam com diretrizes e recursos federais mas são implementadas principalmente pelos municípios. No entanto, com exceção das áreas acima referidas, as relações intergovernamentais são altamente competitivas, tanto vertical como horizontalmente, e marcadas pelo conflito. Mecanismos cooperativos tendem a depender de iniciativas federais ${ }^{17}$. Apesar de a Constituição prover vários mecanismos que sinalizam no sentido do federalismo cooperativo, tais como as competências concorrentes acima mencionadas, o federalismo brasileiro tende a ser altamente competitivo e sem canais institucionais de intermediação de interesses e de negociação de conflitos.

Já que nosso sistema federativo é altamente competitivo, como são resolvidos os conflitos entre esferas de governo? Cabe ao STF esse papel pela sua competência de controle de constitucionalidade, por meio das ações diretas de inconstitucionalidade (ADINs). A lista de instituições que podem propor ADINs foi consideravelmente ampliada pela Constituição de 1988: Presidente da República; mesas do Senado Federal, da Câmara dos Deputados e das assembléias legislativas; governadores; Procurador-Geral da República; Conselho Federal da Ordem dos Advogados do Brasil; partido político com representação no Congresso Nacional e confederação sindical ou entidade de classe de âmbito nacional. Os governadores são os mais ativos proponentes de ADINs, mas grande parte das ações ocorreu em 1990, após a promulgação das constituições estaduais ${ }^{18}$. Paradoxalmente, essas ações não

17 Um exemplo é a gestão de bacias hidrográficas, que conta com a participação de todas as esferas de governo por exigência de legislação federal.

18 Entre 1988 e 2004, foram requeridas 3120 ADINs, das quais $26 \%$ pelos governadores (BRASIL. SUPREMO TRIBUNAL FEDERAL, 2005). objetivavam defender a autonomia dos estados frente à legislação federal, mas sim pedir o reconhecimento judicial da inconstitucionalidade de decisões tomadas pelas assembléias constituintes estaduais ${ }^{19}$

\section{ESTRUTURAE FUNCIONAMENTO DA FE- DERAÇÃO}

\section{V.1. Instituições gerais}

O sistema presidencial sempre foi a opção preferencial dos constituintes brasileiros, exceto por 14 meses, entre 1961 e 1963. Várias tentativas foram feitas a favor do sistema parlamentarista, inclusive durante a constituinte e em 1990, quando os eleitores foram convocados para decidir, por plebiscito, sobre a mudança do sistema, mas a opção pelo presidencialismo sempre foi vitoriosa.

Exceto durante os períodos autoritários, a separação entre os poderes da República foram princípios proeminentes das constituições. Todavia, e como ocorre na maioria dos sistemas presidencialistas, o poder Executivo tem sido o principal iniciador de legislação.

Prevalece um sistema de freios e contrapesos complexo. O STF pode declarar a inconstitucionalidade de lei aprovada pelos poderes executivos federal e estaduais e anular decisões tomadas pelo Congresso Nacional. Os recursos do poder Judiciário provêm do orçamento federal aprovado pelo Congresso. Medidas que podem ser iniciadas apenas pelo Executivo têm que ser submetidas ao Congresso. A Câmara dos Deputados pode instaurar processo contra o Presidente da República, cujo julgamento cabe ao Senado Federal. Este, por sua vez, é a instituição que mais detém competências no sistema de freios e contrapesos, sendo responsável pelo julgamento de membros do STF, pela ratificação de nomes indicados pelo Presidente da República para vários cargos no poder Executivo e pela decisão sobre pedidos de empréstimos internos e externos dos três níveis de governo.

19 Sobre esse ponto, ver o detalhado trabalho de Werneck Vianna (1999). 


\section{V.2. Poder Executivo federal}

Composto pelo Presidente da República e pelos ministros, o poder Executivo possui o maior número de competências exclusivas, compreendendo 25 itens do artigo 21 da Constituição Federal de 1988. Essas competências vão desde aquelas comuns aos sistemas presidencialistas, tais como relações exteriores, defesa nacional e política monetária, até várias áreas específicas de políticas públicas, sobre as quais o poder Executivo tem a competência de aprovar diretrizes, direcionando, portanto, as políticas públicas. Como indicado acima, não existem dispositivos constitucionais regulando a cooperação entre a União e os estados ou sua consulta mútua.

Apesar de a Constituição de 1988 ter aumentado o número daqueles que podem iniciar proposta de legislação (parlamentares federais, Presidente da República, membros do STF e dos tribunais superiores, Procurador-Geral da República e cidadãos (estes com a assinatura de pelo menos $1 \%$ do eleitorado distribuído por pelo menos cinco estados), somente a União pode propor legislação sobre os 29 itens que estão detalhados no artigo 22 da Constituição de 1988. Também cabe exclusivamente à União propor legislação sobre questões listadas como sendo concorrentes entre os três níveis de governo, tais como energia elétrica, trânsito, transporte, mineração e educação. Essa aparente contradição mostra, mais uma vez, a tendência à uniformização acima mencionada, mas também a necessidade de implantar padrões nacionais para várias políticas públicas. Matérias de legislação concorrente entre a União e os estados, excluídos os municípios, estão listados no artigo 24, embora vários itens integrem as competências concorrentes entre os três níveis de governo.

\section{V.3. Poder Judiciário federal}

As constituições brasileiras sempre refletiram a tradição jurídica do Direito Romano-germânico ou Direito Continental e não a do Direito Consuetudinário (Common Law), assim como sempre preservaram a separação entre as instâncias judiciais federais e estaduais.

O sistema federal é integrado por várias instâncias: o STF, o Superior Tribunal de Justiça (STJ), os tribunais regionais federais, a Justiça do Trabalho, a Justiça Eleitoral e a Justiça Militar. O STF é a mais alta corte da federação e desde
1988 combina as competências de uma típica corte constitucional com a de julgamento de certos tipos de recursos. Do ponto de vista federativo, suas competências incluem o controle de constitucionalidade de leis e normas federais e estaduais, o julgamento de conflitos entre o governo federal e os governos estaduais, entre dois ou mais governos estaduais e entre os governos estaduais e suas assembléias legislativas, assim como a constitucionalidade de leis municipais. Isso significa que o STF pode anular leis federais, estaduais e municipais interpretadas por seus membros como inconstitucionais. Diferentemente de muitos países, o STF não possui papel consultivo. O STJ tem a competência de julgar conflitos administrativos entre dois ou mais estados.

\section{V.4. Instituições estaduais}

As instituições estaduais guardam grande semelhança com as federais, com exceção do bicameralismo. O número de deputados estaduais e os critérios para sua remuneração são determinados pela Constituição de 1988. Apesar de os estados possuírem relativamente escassa capacidade legislativa, eles (a) coletam o maior imposto em termos de volume de arrecadação, o ICMS (Imposto sobre Circulação de Mercadorias e Prestação de Serviços de Transporte Interestadual e Intermunicipal e de Comunicação), que, diferentemente de muitas federações, é de competência estadual, assim como determinavam livremente, até a Emenda Constitucional n. 42/2003, suas alíquotas; (b) administram mais recursos do que no regime anterior, embora sua participação na receita pública total tenha declinado nos últimos anos, e (c) possuem efetiva autonomia administrativa. No entanto, a capacidade decisória, financeira e administrativa dos estados é desigual devido às diferenças econômicas entre as regiões.

Assim como acontece na relação entre a União e os estados, inexistem provisões constitucionais regulando as relações entre os estados. Diferentemente de federações como Austrália, Bélgica, Alemanha, EUA, México e África do Sul, não existem conselhos intergovernamentais envolvendo os estados. As exceções são o Conselho Nacional de Política Fazendária (Confaz), que reúne os secretários das finanças dos estados mas que não é previsto na Constituição, e a participação de governadores de estados economicamente menos desenvolvidos em conselhos deliberativos de agências federais de desenvolvimento regional. Alguns 
programas federais são desenhados para contar com a participação de representantes dos estados, mas tais estruturas só se materializam por iniciativa do governo federal e quando estão envolvidas transferências de recursos federais.

\section{V.5. Instituições municipais}

As regras que regem os governos municipais estão escritas na Constituição federal, inclusive as relativas a seus recursos. Assim como acontece com os estados, a capacidade dos governos locais de implementar políticas e de arrecadar recursos próprios é altamente diferenciada. Também como ocorre com os estados, o número de vereadores e os critérios para sua remuneração são determinados por legislação federal. Com a Constituição de 1988, os municípios passaram a ser regidos por leis orgânicas próprias, elaboradas pelos seus respectivos legislativos.

A partir de meados dos anos 1990, os governos locais passaram a ser os principais provedores dos serviços de saúde e de educação fundamental, a partir de regras e de recursos federais, as quais visam a garantir aos cidadãos locais padrões mínimos de atendimento. A adesão dos municípios a essa transferência tem sido avaliada como um sucesso em termos quantitativos, principalmente no que se refere à saúde. Tal sucesso tem sido creditado a uma política concebida como um sistema complexo de relações intergovernamentais que combina incentivos e sanções aos entes subnacionais ${ }^{20}$. Essa transferência pela responsabilidade de implementação é avaliada como tendo reduzido os conflitos entre os governos locais pela disputa pelos recursos federais. Por outro lado, e dado que as políticas de saúde e de educação foram basicamente municipalizadas, as relações intergovernamentais que se estabeleceram são muito mais freqüentes entre a União e os municípios, com participação limitada dos governos estaduais.

Diferentemente do que ocorre nos estados e nos grandes municípios, as relações intermunicipais vêm ocorrendo de maneira cada vez mais crescente, por meio da constituição de inúmeros consórcios, principalmente nas áreas de saúde, proteção ambiental e desenvolvimento econômico.

20 Ver, entre outros, Arretche (2000).
A municipalização não se tem restringido aos governos como provedores de políticas sociais, mas também às comunidades locais. Vários programas federais e outros financiados com recursos de agências multilaterais exigem a constituição de conselhos comunitários para o repasse de recursos. A Constituição de 1988 abriu o caminho para essa participação e para a municipalização por ter incorporado o princípio - que se aplica à maioria das políticas sociais - de que elas deveriam ser descentralizadas e participativas.

\section{SISTEMA FISCAL}

\section{VI.1. Sistema tributário}

A Constituição assegura capacidade de tributar aos três níveis de governo. Alguns impostos e contribuições são exclusivos da esfera que os arrecada, outros são coletados pela União e partilhados com estados e municípios, outros ainda são coletados pelos estados e partilhados com os municípios. A Constituição não autoriza nenhum nível de governo a criar novos impostos sem emendas à Constituição, embora existam duas exceções que se aplicam à União: em caso de iminência de guerra ou para financiar o sistema de seguridade social, embora a última requeira a aprovação do Congresso Nacional, mas sem o quorum de supermaioria requerido pelas emendas constitucionais. As regras e mesmo as alíquotas de alguns impostos, inclusive estaduais e municipais, são determinadas pela instância federal.

Um princípio constitucional merece registro pelo seu caráter federativo. Trata-se da proibição a qualquer nível de governo cobrar imposto sobre o patrimônio, renda ou serviços uns dos outros, garantindo, assim, imunidade intergovernamental do ponto de vista da taxação.

A distribuição dos recursos tributários, apesar de hoje muito mais concentrada na União do que quando da promulgação da Constituição de 1988, assegura às esferas subnacionais cerca de $32 \%$ de todos os impostos coletados no país. Com as transferências, elas recebem $43 \%$ das receitas totais. Do lado das despesas, os governos subnacionais são responsáveis por 70\% (10,1\% do produto interno bruto (PIB)) da despesa com pessoal e por $80 \%$ da formação bruta de capital fixo (2,2\% do PIB) (AFONSO, 2004, p. 5).

\section{VI.2. Empréstimos}

Para contrair empréstimos, os três níveis pre- 
cisam da autorização de seus respectivos legislativos e da aprovação do Banco Central e do Senado Federal. A promulgação da Lei de Responsabilidade Fiscal (LRF), em 2000, e de um conjunto de outras leis ordinárias federais tornou quase impossível a contratação de novos empréstimos, em especial pelos governos subnacionais. É importante notar que uma das maiores fontes de financiamento dos governos estaduais para a realização de investimentos, os organismos multilaterais, não estão sujeitos aos limites da LRF.

Como se sabe, a dívida pública tem sido um sério constrangimento não só para as contas públicas mas para o próprio crescimento econômico do país. Antes dos ajustes promovidos no final dos anos 1990, os estados eram os maiores devedores, representando $42 \%$ da dívida pública total. Essa dívida foi federalizada, embora os estados aloquem cerca de $13 \%$ da sua receita líquida real para seu pagamento.

\section{VI.3. Alocação de recursos}

A despeito dos esforços dos constituintes, a concentração de recursos na União retornou a antigos patamares, assim como a concentração de atividades econômicas em algumas regiões e espaços territoriais. Isso não significa que um sistema de melhor equalização fiscal não tenha sido tentado nas constituições anteriores; a Constituição de 1988 aprofundou o complexo sistema de transferências intergovernamentais de recursos com objetivos redistributivos. Introduzido pelos militares mai aumentando pela Constituição de 1988, parcelas de dois impostos federais, o IR (Imposto sobre a Renda e Proventos de Qualquer Natureza) e o IPI (Imposto sobre Produtos Industrializados), são transferidas por meio de fundos de participação, com o objetivo de diminuir as diferenças econômicas entre as regiões. Os estados recebem $21,5 \%$ dessas transferências, sendo que $85 \%$ são destinados às regiões Norte, Nordeste e Centro-Oeste e os restantes $15 \%$ às regiões Sul e Sudeste. A fórmula para determinar a quota de cada estado leva em consideração o tamanho da população e o inverso da renda per capita. Os municípios recebem $22,5 \%$, sendo que, desse valor, $10 \%$ destinam-se às capitais. A distribuição dos restantes $90 \%$ também leva em conta a população e o inverso da renda per capita. Apesar de visarem melhor equalização fiscal, essas transferências estão longe de aproximarem-se dos sistemas de equalização vigentes em países como Canadá, Alemanha e Suíça.
Existem também outros mecanismos de transferências federais para as esferas subnacionais. Aprovadas por emendas constitucionais de 1996 e 2000, essas transferências são vinculadas às políticas nacionais de educação fundamental e saúde. Transferências negociadas também são realizadas entre o governo federal e as esferas subnacionais e entre os estados e seus municípios. No entanto, a política de ajuste fiscal vem reduzindo a importância relativa e absoluta dessas transferências.

Outros dispositivos constitucionais também buscam enfrentar as desigualdades regionais, tais como (a) a determinação da aplicação de um percentual das transferências federais nas regiões Norte, Nordeste e Centro-Oeste e (b) a regionalização do orçamento federal a fim de dar transparência aos gastos federais em cada região. Todas essas iniciativas, todavia, não são ainda suficientes para diminuir os desequilíbrios horizontais, tanto em termos absolutos como relativos.

\section{MUDANÇAS CONSTITUCIONAIS ${ }^{21}$}

Desde a promulgação da Constituição de 1988, sua reforma esteve na agenda de vários organismos públicos, privados e multilaterais, inclusive os governos, tornando-a a mais emendada Constituição brasileira. A Constituição de 1988 conta hoje com 42 emendas, mais seis de revisão, estas aprovadas por maioria simples porque realizadas em 1994 durante o período constitucionalmente previsto para sua revisão. Embora o número de votos requerido para a aprovação de emendas seja baixo em comparação com outros países (três quintos), exigem-se votações nominais em dois turnos.

Devido ao fato de que os constituintes concentraram seus esforços na criação de regras capazes de legitimar o novo regime democrático, com escassa preocupação com questões de natureza macro-econômica, a maioria das emendas, em especial as de mais difícil negociação, foi dedicada a reformulações voltadas para atender aos novos objetivos da política macro-econômica. As regras relativas ao federalismo também foram afetadas pelas mudanças que ocorreram na

\footnotetext{
21 Para uma análise sobre as principais reformas constitucionais, ver Melo (2002) e Couto e Arantes (2003).
} 
agenda política do país com a abertura da economia.

As emendas constitucionais que afetam as relações entre governos promoveram mudanças no que foi desenhado originalmente. Essas mudanças (a) impuseram limites na liberdade das instâncias subnacionais de aplicar recursos próprios, como resultado da política de ajuste fiscal; (b) vincularam parcela das receitas subnacionais à aplicação nos serviços de saúde e educação fundamental e (c) reduziram os recursos federais sem vinculações transferidos para estados e municípios. Emendas e outras leis infraconstitucionais também criaram novas contribuições e aumentaram as alíquotas de algumas já existentes, mas que não são partilhadas com as esferas subnacionais, reduzindo a participação dos recursos à disposição dos entes subnacionais vis-à-vis a esfera federal.

As emendas aprovadas a partir de meados dos anos 1990 buscaram adaptar o país a questões que não estavam na agenda nem dos constituintes nem da transição democrática, tais como a globalização e o ajuste fiscal.

\section{COMENTÁRIOS FINAIS}

A experiência brasileira de sete constituições em pouco menos de um século demonstra as dificuldades do país para sustentar a governança constitucional, ameaçada quando o ambiente político e econômico é reestruturado ou quando o sistema político torna-se incapaz de encaminhar alternativas para grandes crises ou realinhamentos. Apesar de a constitucionalização de número significativo de questões limitar o espaço de manobra dos grupos políticos e dos governos, o constitucionalismo brasileiro muitas vezes não foi capaz de sustentar o regime democrático, nem tampouco de encaminhar soluções para um dos problemas cruciais da prática do federalismo no Brasil, que são as desigualdades econômicas entre as regiões.

Apesar dessas limitações, a federação foi fortalecida com a Constituição de 1988 por ter promovido maior equilíbrio entre seus entes constitutivos. No entanto, as regras constitucionais continuam submetidas a dois tipos de tensão. A primeira vem das novas demandas macro-econômicas trazidas pelas mudanças no ambiente internacional e que exigem, entre outras medidas, rígido controle fiscal e superávits primários. Tal tensão limita, obviamente, os recursos governa- mentais para serem usados em políticas de correção das desigualdades regionais, elevando a tensão entre a demanda macro-econômica por controle fiscal versus a demanda federativa por menor desigualdade regional. A segunda provém do fato de que o alto grau de constitucionalização contradiz o timing requerido pela nova agenda macro-econômica. Isso porque mudanças nas regras constitucionais que afetam o status quo requerem longas negociações com o Congresso Nacional. No entanto, tais negociações têm sido, em geral, favoráveis ao poder Executivo federal. Essas mudanças, todavia, ainda são submetidas ao julgamento de constitucionalidade por parte do STF.

Além das tensões referidas acima, os problemas atuais do federalismo e do constitucionalismo no Brasil apontam para três questões. A primeira, e mais importante, é que a federação está assentada em alto grau de desigualdade entre as regiões, a despeito das medidas constitucionais que buscam diminuí-la. Tal desigualdade é histórica e parece que soluções para minimizá-la vão requerer prolongadas negociações e longo tempo para seus efeitos serem sentidos - isso se e quando entrarem na agenda política e não apenas durante a elaboração de novas regras constitucionais. Ainda relacionada a essa questão, a abertura da economia brasileira também tende a aumentar a distância econômica entre os estados 22

A segunda relaciona-se à tendência ao tratamento uniforme das esferas subnacionais, em particular os estados, associada à maior redução relativa de suas receitas, inclusive pelo pagamento de suas dívidas com a União, federalizadas no final dos anos 1990. Paralelamente, existem hoje relações diretas entre o governo federal e os municípios decorrentes da descentralização das políticas sociais. Esses fatores limitam a capacidade de iniciativa dos governos estaduais, inclusive no que se refere a novos investimentos tanto em infraestrutura como nas áreas sociais.

A terceira questão é a escassa existência de mecanismos de coordenação e cooperação intergovernamentais, tanto vertical como horizontal, coibindo a criação de canais de negociação

22 O Sudeste responde por $55 \%$ das exportações brasileiras, o Sul por $26 \%$, o Nordeste por $8 \%$, o Norte por $6 \%$ e o Centro-Oeste por 5\% (AFONSO, 2004, p. 16). 
que diminuam a competição entre os entes federados.

A síntese que pode ser feita é que a solução para os principais problemas que afetam o federalismo brasileiro depende menos de como o federalismo está hoje desenhado na Constituição e das instituições que o modelam do que (a) do encaminhamento de conflitos políticos mais amplos, em que o das desigualdades regionais inscrevese, e (b) da redefinição de prioridades governamentais - tema, portanto, do território das políticas públicas e não da Constituição.

Celina Souza (celina@ufba.br) é Doutora em Ciência Política pela London School of Economics and Political Science (LSE) e pesquisadora do Centro de Recursos Humanos (CRH) da Universidade Federal da Bahia (UFBA).

\section{REFERÊNCIAS BIBLIOGRÁFICAS}

ABRUCIO, F. L. 1998. Os barões da federação. São Paulo : Hucitec.

AFONSO, J. R. 2004. Brasil, um caso à parte. Trabalho apresentado no XVI Regional Seminar of Fiscal Policy, organizado pela Comissão Econômica para a América Latina e o Caribe e realizado em Santiago do Chile, em 13.set. Digit.

AGRANOFF, R. 2003. Intergovernmental Policy Management. Trabalho apresentado na Conferência Internacional "Which Federalism?”, realizado em Savelletri (Itália), em 22 a 27.mar. Digit.

ALMEIDA, M. H. T. 2001. Federalismo, democracia e governo no Brasil : idéias, hipóteses, evidências. BIB, Rio de Janeiro, n. 51, p. 13-34.

AMES, B. 1987. Political Survival : Politicians and Public Policy in Latin America. Berkeley : University of California.

2000. The Deadlock of Democracy in Brazil. Ann Arbor : University of Michigan.

ARRETCHE, M. 2000. Estado federativo e políticas sociais : determinantes da descentralização. Rio de Janeiro : Revan.

BERCOVICI, G. 2003. Desigualdades regionais, Estado e Constituição. São Paulo : M. Limonad.

CARVALHO, J. M. 1993. Federalismo y centralización em el imperio brasileño. In : CARMAGNANI, M. (coord.). Federalismos latinoamericanos : México, Brasil, Argentina. Ciudad de México : El Colégio de México.

Couto, C. G. \& ARANTES, R. B. 2003.
Constituición o políticas públicas? Una evaluación de los años FHC. In : PALERMO, V. (comp.) Política brasileña contemporánea : de Collor a Lula en años de transformación. Buenos Aires : Siglo XXI.

EVANS, M. 2001. Studying the New Constitutionalism : Bringing Political Science Back In. British Journal of Politics and International Relations, v. 3, n. 3, p. 413-426.

FIGUEIREDO, A. \& LIMONGI, F. 1999. Executivo e Legislativo na nova ordem constitutional. Rio de Janeiro : Fundação Getúlio Vargas.

GIBSON, E. 2004. Federalism and Democracy : Theoretical Connections and Cautionary Insights. In :__ . (ed.). Federalism and Democracy in Latin America. Baltimore : Johns Hopkins University.

GIBSON, E. \& FALLETI, T. 2004. Unity by the Stick : Regional Conflict and the Origins of Argentine Federalism. In : GIBSON, E. (ed.). Federalism and Democracy in Latin America. Baltimore : Johns Hopkins University.

GRAHAM, L. 1987. The Role of the States in Brazilian Federation. In : PICARD, L. \& ZARISKI, R. (eds.). Subnational Politics in the 1980s : Organization, Reorganization and Economic Development. New York : Harvester Wheatsheaf.

GRIFFITHS, A. L. 2002. Handbook of Federal Countries, 2002. Montreal : Forum of Federations.

KUGELMAS, E.; SALLUM JÚNIOR, B. \& GRAEFF, E. 1989. Conflito federativo e tran- 
sição política. São Paulo em Perspectiva, v. 3, n. 3, p. 95-102.

LIMONGI, F. 1989. "O federalista” : remédios republicanos para males republicanos. In : WEFFORT, F. (org.). Os clássicos da política : Maquiavel, Hobbes, Locke, Montesquieu, Rousseau, "O federalista”. São Paulo : Ática.

LOVE, J. L. 1993. Federalismo y regionalismo en Brasil, 1889-1937. In : CARMAGNANI, M. (coord.). Federalismos latinoamericanos : México, Brasil, Argentina. Ciudad de México : El Colégio de México.

MAHAR, D. J. 1976. Federalismo fiscal no Brasil : a experiência histórica. In : REZENDE, F. (org.). Política fiscal e programação dos gastos do governo. Rio de Janeiro : Instituto de Pesquisas Econômicas Aplicadas.

MAINWARING, S. 1999. Rethinking Party Systems in the Third Wave of Democratization: The case of Brazil. Stanford : Stanford University.

MEDEIROS, A. C. 1986. Politics and Intergovernmental Relations in Brazil, 19641982. New York : Garland.

MELO, M. A. 1993. Municipalismo, nationbuilding e a modernização do Estado no Brasil. Revista Brasileira de Ciências Sociais, São Paulo, v. 23, n. 8, p. 83-100.

2002. Reformas constitucionais no Brasil : instituições políticas e processo decisório. Rio de Janeiro : Revan.

MELLO, D. L. 1976. O controle dos governos municipais. Revista de Administração Municipal, Rio de Janeiro, v. 36, p. 27-42.

PALERMO, V. 2000. Como se governa o Brasil? O debate sobre instituições políticas e gestão de governo. Dados, Rio de Janeiro, v. 43, n. 3, p. $580-691$.

REZENDE, F. 1976. Finanças públicas e transferências intergovernamentais. In : . (org.). Política fiscal e programação dos gastos do governo. Rio de Janeiro : Instituto de Pesquisas Econômicas Aplicadas.

RIKER, W. 1975. Federalism. In : GREENSTEIN, F. \& POLSBY, N. (eds.). Handbook of Political Science. Reading : Addison-Wesley.
ROSENFELD, M. 2000. American Constitutionalism Confronts Denniger's New Constitutional Paradigm. Constellations, v. 7, n. 4, p. 529-548.

ROSENN, K. 1990. Brazil's New Constitution : An Exercise in Transient Constitutionalism for a Transitional Society. The American Journal of Comparative Law, v. 38, p. 773-802.

SALLUM JÚNIOR, B. 1996. Labirintos : dos generais à Nova República. São Paulo : Hucitec.

SELCHER, W. 1989. A New Start toward a More Decentralized Federalism in Brazil? Publius : The Journal of Federalism, Easton, v. 19, p. 167-183, Summer.

SERRA, J. \& AFONSO, J. R. 1999. Federalismo fiscal à brasileira : algumas reflexões. $R e$ vista do BNDES, Rio de Janeiro, v. 6, n. 12, p. 12-32.

SOUZA, C. 1997. Constitutional Engineering in Brazil : The Politics of Federalism and Decentralization. London : Macmillan.

2001a. Federalismo e gasto social no Brasil : tensões e tendências. Lua Nova, São Paulo, n. 52, p. 5-28.

2001b. Federalismo e descentralização na Constituição de 1988 : processo decisório, conflitos e alianças. Dados, Rio de Janeiro, v. 44, n. 3, p. 513-560.

2002. Brazil : The Prospects of a CenterConstraining Federation in a Fragmented Polity. Publius : The Journal of Federalism, Easton, v. 32, n. 2, p. 23-48, Spring.

2003. Federalismo e conflitos distributivos : disputa dos estados por recursos orçamentários federais. Dados, Rio de Janeiro, v. 46, n. 2, p. 345-384.

STEPAN, A. 2000. Brazil's Decentralized Federalism : Bringing Government Closer to the Citizens? Daedalus, Cambridge, Mass., v. 129, n. 2, p. 145-169, Spring.

VALENTE, W. (org.). 2001. Cases and Materials on State and Local Government Law. St. Paul : West Group.

WERNECK VIANNA, L. (org.). 1999. A judicialização da política e das relações sociais no Brasil. Rio de Janeiro : Revan. 


\section{OUTRAS FONTES}

BRASIL. 1988. Constituição da República Federativa do Brasil. Brasília : Senado Federal. Disponível

em

https://

www.presidencia.gov.br/casacivil/site/static/ le.htm. Acesso em : 15.jun.2004.
BRASIL. Supremo Tribunal Federal. 2005. Ações diretas de inconstitucionalidade - 1988 a 2005 - por requerente. Brasília : Supremo Tribunal Federal. Disponível em : http:// www.stf.gov.br/bndpj/stf/AdinReq.asp. Acesso em : 23.maio.2005. 
Versão dos resumos para o inglês: Miriam Adelman

FEDERALISM, CONSTITUTIONAL DESIGN, AND FEDERATIVE INSTITUTIONS IN BRAZIL AFTER 1988

\section{Celina Souza}

This article analyzes constitutional mechanisms regarding federalism throughout the history of the Brazilian constitution. We seek to reconcile the analysis of how Brazilian federalism functions in practice with the constitutional mechanisms that, on paper, establish this institution. The Brazilian federation's various constitutional designs are described, focusing primarily on the 1988 Federal Constitution and its amendments. We argue that the main constraints that Brazilian federalism must face today are more a consequence of governments' difficulties in redirecting the route of certain public policies and in dealing with macro-economic issues that had not been anticipated by the 1988 constitutional congress than of problems related to constitutional design

KEYWORDS: federalism; constitutionalism; Brazil. 
Versão dos resumos para o francês: Maria Fernanda Araújo Lisboa FÉDÉRALISME, DESSIN CONSTITUTIONNEL ET INSTITUTIONS FÉDÉRATIVES DANS LE BRÉSIL APRÈS 1988

Celina Souza

Cet article analyse les dispositifs constitutionnels concernant le fédéralisme au long de l'histoire constitutionnelle brésilienne. Il cherche à concilier l'analyse sur comment le fédéralisme brésilien fonctionne réellement et les dispositifs constitutionnels qui sont attribués à cette institution. Sont décrits les divers dessins constitutionnels de la fédération brésilienne et pour cela on s’appuie surtout sur la constitution fédérale de 1988 et ses amendes. L'article argumente que les principales contraintes auxquelles le fédéralisme brésilien doit aujourd'hui faire face découlent plutôt des difficultés des gouvernements de reorienter certaines politiques publiques et de traiter des questions macroéconomiques pas prévues par les constituants de 1988 que des problèmes originaires du dessin constitutionnel.

MOTS-CLÉS : fédéralisme; constitutionnalisme; Brésil. 